\title{
Paclitaxel-Eluting Stents versus Bare-Metal Stents in Acute Myocardial Infarction
}

\author{
Gregg W. Stone, M.D., Alexandra J. Lansky, M.D., Stuart J. Pocock, Ph.D., \\ Bernard J. Gersh, M.B., Ch.B., D.Phil., George Dangas, M.D., Ph.D., \\ S. Chiu Wong, M.D., Bernhard Witzenbichler, M.D., Giulio Guagliumi, M.D., \\ Jan Z. Peruga, M.D., Bruce R. Brodie, M.D., Dariusz Dudek, M.D., \\ Martin Möckel, M.D., Andrzej Ochala, M.D., Alison Kellock, B.S., \\ Helen Parise, Sc.D., and Roxana Mehran, M.D., \\ for the HORIZONS-AMI Trial Investigators*
}

ABSTRACT

From Columbia University Medical Center and New York-Presbyterian Hospital and the Cardiovascular Research Foundation (G.W.S., A.J.L., G.D., A.K., H.P., R.M.), and New York-Presbyterian Hospital and Weill Cornell Medical Center (S.C.W.) - all in New York; London School of Hygiene and Tropical Medicine, London (S.J.P.); Mayo Clinic, Rochester, MN (B.J.G.); Charité Campus Benjamin Franklin (B.W.) and Charité Campus Virchow-Klinikum (M.M.) — both in Berlin; Ospedali Riuniti di Bergamo, Bergamo, Italy (G.G.); Medical University, Lodz (J.Z.P.), Jagiellonian University, Krakow (D.D.), and Silesian Medical Academy, Katowice (A.O.) - all in Poland; and LeBauer Cardiovascular Research Foundation and Moses Cone Hospital, Greensboro, NC (B.R.B.). Address reprint requests to $\mathrm{Dr}$. Stone at Columbia University Medical Center, Cardiovascular Research Foundation, 111 E. 59th St., 11th Fl., New York, NY 10022, or at gs2184@ columbia.edu.

*The investigators, institutions, and research organizations participating in the Harmonizing Outcomes with Revascularization and Stents in Acute Myocardial Infarction (HORIZONS-AMI) trial are listed in the Appendix.

N Engl J Med 2009;360:1946-59.

Copyright (C) 2009 Massachusetts Medical Society.

\section{BACKGROUND}

There is no consensus regarding the safety and efficacy of drug-eluting stents, as compared with bare-metal stents, in patients with ST-segment elevation myocardial infarction who are undergoing primary percutaneous coronary intervention (PCI).

\section{METHODS}

We randomly assigned, in a 3:1 ratio, 3006 patients presenting with ST-segment elevation myocardial infarction to receive paclitaxel-eluting stents (2257 patients) or otherwise identical bare-metal stents (749 patients). The two primary end points of the study were the 12-month rates of target-lesion revascularization for ischemia (analysis powered for superiority) and a composite safety outcome measure of death, reinfarction, stroke, or stent thrombosis (powered for noninferiority with a 3.0\% margin). The major secondary end point was angiographic evidence of restenosis at 13 months.

\section{RESULTS}

Patients who received paclitaxel-eluting stents, as compared with those who received bare-metal stents, had significantly lower 12-month rates of ischemia-driven targetlesion revascularization (4.5\% vs. $7.5 \%$; hazard ratio, 0.59 ; $95 \%$ confidence interval [CI], 0.43 to $0.83 ; \mathrm{P}=0.002)$ and target-vessel revascularization $(5.8 \%$ vs. $8.7 \%$; hazard ratio, 0.65 ; $95 \% \mathrm{CI}, 0.48$ to $0.89 ; \mathrm{P}=0.006$ ), with noninferior rates of the composite safety end point (8.1\% vs. $8.0 \%$; hazard ratio, 1.02; $95 \%$ CI, 0.76 to 1.36; absolute difference, 0.1 percentage point; $95 \% \mathrm{CI},-2.1$ to 2.4 ; $\mathrm{P}=0.01$ for noninferiority; $\mathrm{P}=0.92$ for superiority). Patients treated with paclitaxel-eluting stents and those treated with bare-metal stents had similar 12-month rates of death $(3.5 \%$ and $3.5 \%$, respectively; $\mathrm{P}=0.98$ ) and stent thrombosis $(3.2 \%$ and $3.4 \%$, respectively; $\mathrm{P}=0.77)$. The 13-month rate of binary restenosis was significantly lower with paclitaxel-eluting stents than with bare-metal stents $(10.0 \%$ vs. $22.9 \%$; hazard ratio, $0.44 ; 95 \% \mathrm{CI}$, 0.33 to $0.57 ; \mathrm{P}<0.001)$.

\section{CONCLUSIONS}

In patients with ST-segment elevation myocardial infarction who were undergoing primary PCI, implantation of paclitaxel-eluting stents, as compared with bare-metal stents, significantly reduced angiographic evidence of restenosis and recurrent ischemia necessitating repeat revascularization procedures. No safety concerns were apparent at 1 year. (ClinicalTrials.gov number, NCT00433966.) 
Y ENLARGING LUMINAL DIMENSIONS and sealing dissection planes at the site of coronary-artery occlusion in patients with evolving ST-segment elevation myocardial infarction, bare-metal stents reduce the risk of early and late recurrent ischemia and reocclusion of the infarct-related artery, as compared with balloon angioplasty alone, decreasing the need for subsequent revascularization of the target lesion with repeat percutaneous coronary intervention (PCI) or coronary-artery bypass grafting. ${ }^{1,2}$ Nonetheless, restenosis occurs in more than $20 \%$ of patients in whom bare-metal stents are implanted during primary PCI, and implantation of bare-metal stents, as compared with balloon angioplasty, has not reduced the rates of death or reinfarction among patients with ST-segment elevation myocardial infarction. ${ }^{1,2}$ As compared with bare-metal stents, drug-eluting stents reduce neointimal hyperplasia and have been shown in large, randomized trials to be safe and effective for the treatment of simple lesions in patients with stable coronary-artery disease. ${ }^{3,4}$ As would be expected, however, the rates of target-lesion revascularization, stent thrombosis, and death are increased when drug-eluting stents are used in higher-risk patients and those with more complex lesions. ${ }^{5,6}$ Specifically, when drug-eluting stents are implanted in ruptured plaques with a large necrotic core (the lesion substrate responsible for most cases of ST-segment elevation myocardial infarction), ${ }^{7}$ they may impair vascular healing responses, potentially resulting in increased rates of stent thrombosis. ${ }^{8,9}$ Reduced rates of target-lesion revascularization with drug-eluting stents, as compared with bare-metal stents, in patients with ST-segment elevation myocardial infarction have been reported in small-to-moderate-size randomized trials $^{10}$; none, however, were powered for safety end points, and the routine performance of follow-up angiography may have exaggerated the benefits of drug-eluting stents in many of these studies. ${ }^{11,12}$

To address these limitations, we performed a large-scale, international, prospective, randomized trial comparing paclitaxel-eluting stents with bare-metal stents in patients with evolving STsegment elevation myocardial infarction. The study was powered for safety as well as efficacy, with follow-up angiographic assessment performed only after the primary clinical end point had been evaluated.

\section{METHODS}

\section{STUDY DESIGN}

The Harmonizing Outcomes with Revascularization and Stents in Acute Myocardial Infarction (HORIZONS-AMI) trial was a prospective, openlabel, multicenter, controlled trial involving patients with ST-segment elevation myocardial infarction who were undergoing primary PCI as a management strategy. The study incorporated two factorial randomized phases to allow a comparison of the direct thrombin inhibitor bivalirudin alone with heparin plus glycoprotein IIb/IIIa inhibitors and a comparison of paclitaxel-eluting stents with bare-metal stents. ${ }^{13,14}$ The trial was designed by the principal investigator, executive committee, and pharmacology committee and was sponsored and managed by the Cardiovascular Research Foundation, a nonprofit foundation affiliated with Columbia University, with grant support from Boston Scientific Corporation and the Medicines Company. Other than supplying financial support and the drugs and devices, the funding companies were not involved with study processes, including site selection and management, data collection, and analysis. The principal investigator had unrestricted data access after the database was locked, controlled the decision to submit the findings for publication, prepared the manuscript, and vouches for the integrity of the data.

\section{PATIENT POPULATION AND RANDOMIZATION}

Consecutive patients 18 years of age or older who presented within 12 hours after the onset of symptoms and who had ST-segment elevation of $1 \mathrm{~mm}$ or more in two or more contiguous leads, new left bundle-branch block, or true posterior myocardial infarction were considered for enrollment. The clinical exclusion criteria, which have been described previously, were contraindications to study medications, conditions that increase the risk of hemorrhage, and an inability to take clopidogrel for 6 months after the procedure. ${ }^{13,14}$ The study was approved by the institutional review board or ethics committee at each participating center, and all patients gave written informed consent.

Eligible patients were randomly assigned in a 1:1 ratio to treatment with unfractionated heparin plus a glycoprotein IIb/IIIa inhibitor or to treatment with bivalirudin alone (Fig. 1); the timing and dosing for each regimen have been de- 
scribed previously. ${ }^{13,14}$ After the first randomization, emergency coronary angiography with left ventriculography was performed, and patients were then assigned, at the discretion of the physician, to treatment with PCI or coronary-artery bypass grafting (CABG) or to medical manage- ment. Among patients undergoing PCI, anatomical eligibility for randomization to stent implantation was assessed after the restoration of patency in the infarct-related vessel (by means of spontaneous reperfusion, guidewire recanalization, or inflation of an undersized angioplasty balloon).

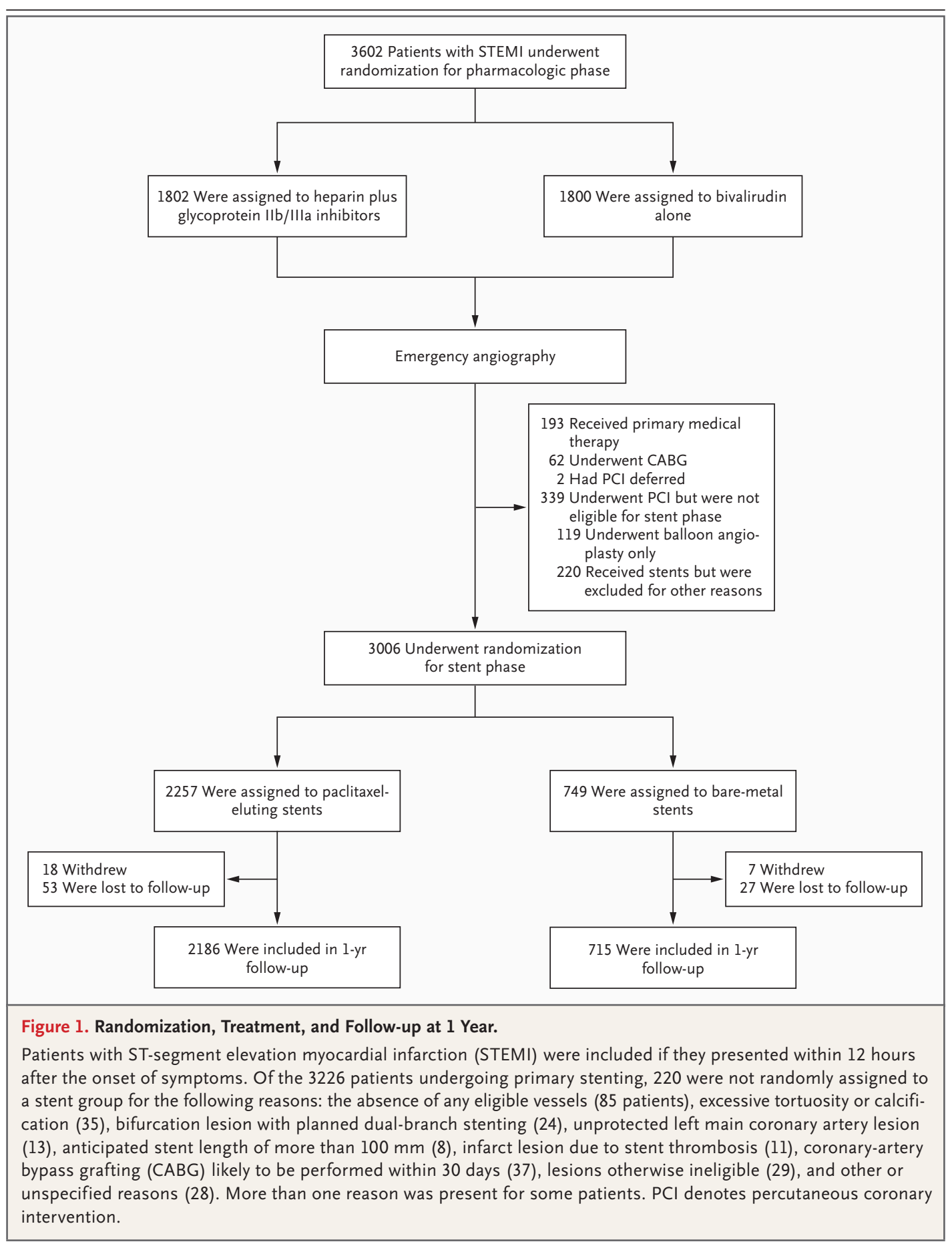


Patients were considered to be eligible for random assignment to paclitaxel-eluting stents or baremetal stents if an acute-infarct-related artery was present in which all lesions requiring PCI had a visually estimated reference-vessel diameter between $2.25 \mathrm{~mm}$ and $4.0 \mathrm{~mm}$, without excessive tortuosity or severe calcification. Angiographic exclusion criteria were planned stenting of an unprotected left main artery (i.e., a left main artery without a patent bypass graft to either the left anterior descending artery or the left circumflex artery), a bifurcation lesion that required planned implantation of stents in both the main vessel and a side branch (bifurcation lesions were included if a single-stent strategy was intended, even if multiple stents were ultimately required), an anticipated stent length of more than $100 \mathrm{~mm}$, infarction due to stent thrombosis, and an anticipated need for bypass grafting within 30 days. Patients with multiple lesions and vessels requiring intervention were included in the study if all the lesions were eligible for study stents.

Patients who were eligible for random assignment to stent implantation were assigned in a 3:1 ratio to receive either paclitaxel-eluting stents (TAXUS Express, Boston Scientific) or otherwise identical bare-metal stents (Express, Boston Scientific) (Fig. 1). Randomization was performed with the use of a computerized, interactive voiceresponse system and a dynamic (minimization) allocation scheme that balanced the assignment for the pharmacologic assignment (unfractionated heparin plus a glycoprotein IIb/IIIa inhibitor or bivalirudin alone), the presence or absence of diabetes mellitus, lesion length $(>26 \mathrm{~mm}$, requiring overlapping stents, vs. $\leq 26 \mathrm{~mm}$ ), and location of the study site (in the United States or outside the United States).

\section{PROTOCOL PROCEDURES}

Stents with a diameter between 100 and $110 \%$ of the distal reference-vessel diameter were implanted, and implantation was performed with a minimum pressure of $14 \mathrm{~atm}$. Direct stenting (i.e., without balloon predilation) was permitted according to the discretion of the physician if the infarct-related vessel was patent (i.e, had a Thrombolysis in Myocardial Infarction [TIMI] flow grade of 2 or 3) at baseline. Study stents were available in diameters ranging from 2.25 to $4.0 \mathrm{~mm}$ and in lengths ranging from 8 to $32 \mathrm{~mm}$.

Aspirin (324 mg administered in chewable form or $500 \mathrm{mg}$ administered intravenously) was given in the emergency room, after which 300 to $325 \mathrm{mg}$ was given orally every day during the hospitalization and 75 to $81 \mathrm{mg}$ every day thereafter indefinitely. A loading dose of clopidogrel (either $300 \mathrm{mg}$ or $600 \mathrm{mg}$, at the discretion of the investigator) was administered before catheterization, followed by $75 \mathrm{mg}$ orally every day for at least 6 months (with a recommendation of 1 year or longer).

Clinical follow-up examinations were performed at 30 days, 6 months, and 12 months, and then yearly for a total of 5 years. The primary clinical end points of the first randomization (pharmacologic phase) were prespecified at 30 days, whereas the primary end points of the second randomization (stent phase) were prespecified at 12 months. Routine angiographic follow-up at 13 months (after ascertainment of the primary 12month clinical end points) was prespecified for 1800 patients randomly assigned to receive a stent in whom implantation of the stent was successful (diameter stenosis $<10 \%$ with a TIMI flow grade of 3 and a National Heart, Lung, and Blood Institute classification for coronary-artery dissection of type A or less adjacent to the stent), stent thrombosis did not occur, and bypass grafting was not performed within 30 days after implantation of the stent.

\section{STATISTICAL ANALYSIS}

Two primary 12-month clinical end points were prespecified: ischemia-driven revascularization of the target lesion and a composite safety end point of major adverse cardiovascular events, consisting of death, reinfarction, stroke, and stent thrombosis. The components of the safety end point have been defined previously. ${ }^{13,14}$ Target-lesion revascularization was considered to be ischemiadriven if there was stenosis of at least $50 \%$ of the diameter of the target lesion, as documented by a positive functional study, ischemic changes on an electrocardiogram, or symptoms referable to the target lesion, or in the absence of documented ischemia, if there was stenosis of at least $70 \%$ as assessed by quantitative coronary analysis at the independent core laboratory. Stent thrombosis was defined as the definite or probable occurrence of a thrombotic event, according to the Academic Research Consortium classification. ${ }^{15}$ An independent clinical events committee whose members were unaware of the treatment assign- 
ments adjudicated all primary end-point events by reviewing original source documents and procedural angiograms. Angiographic analysis was performed at the core laboratory with the use of validated methods by technicians who were unaware of the treatment assignments and clinical outcomes. ${ }^{16}$

The trial was powered to show the superiority of paclitaxel-eluting stents as compared with bare-metal stents for the 12-month primary efficacy end point of target-lesion revascularization and the major secondary efficacy end point of binary restenosis as assessed by angiography at 13 months, with a two-sided alpha level of 0.05 . Assuming 1-year rates of ischemia-driven targetlesion revascularization of $5.0 \%$ in the paclitaxeleluting-stent group and $9.0 \%$ in the bare-metal- stent group, with assignment of 2250 patients and 750 patients to the two groups, respectively, and $95 \%$ of the patients available for the 1-year follow-up, we calculated that the trial would have $95 \%$ power to show the superiority of paclitaxeleluting stents for the primary efficacy end point. Assuming that 1200 patients had follow-up angiograms at 13 months that could be evaluated, the trial would have $96 \%$ power to show a reduction in binary restenosis from $26.0 \%$ with baremetal stents to $15.6 \%$ with paclitaxel-eluting stents. The trial was also powered to show the noninferiority of paclitaxel-eluting stents as compared with bare-metal stents for the primary composite safety end point of major adverse cardiovascular events, on the basis of the upper boundary of the two-sided 95\% confidence inter-

\begin{tabular}{|c|c|c|c|}
\hline Variable & $\begin{array}{l}\text { Paclitaxel-Eluting } \\
\text { Stents ( }=2257)\end{array}$ & $\begin{array}{c}\text { Bare-Metal } \\
\text { Stents ( }=749)\end{array}$ & P Value \\
\hline Age $-y r$ & & & 0.26 \\
\hline Median & 59.9 & 59.3 & \\
\hline Range & $30.9-92.3$ & $26.0-89.0$ & \\
\hline Male sex - no. (\%) & $1738(77.0)$ & $569(76.0)$ & 0.56 \\
\hline \multicolumn{4}{|l|}{ Diabetes - no./total no. (\%) } \\
\hline Any & $364 / 2256(16.1)$ & $114 / 749(15.2)$ & 0.55 \\
\hline Insulin-requiring & $98 / 2256(4.3)$ & $31 / 749(4.1)$ & 0.81 \\
\hline Hypertension — no./total no. (\%) & $1155 / 2256(51.2)$ & $389 / 749(51.9)$ & 0.73 \\
\hline Hyperlipidemia — no./total no. (\%) & $953 / 2256(42.2)$ & $308 / 749(41.1)$ & 0.59 \\
\hline Current smoker — no./total no. (\%) & $1041 / 2246(46.3)$ & $388 / 748(51.9)$ & 0.009 \\
\hline Prior myocardial infarction — no./total no. (\%) & $206 / 2256(9.1)$ & $82 / 749(10.9)$ & 0.14 \\
\hline Prior percutaneous coronary intervention - no./total no. (\%) & $214 / 2255(9.5)$ & $58 / 749(7.7)$ & 0.15 \\
\hline Prior coronary-artery bypass grafting - no./total no. (\%) & $50 / 2256(2.2)$ & $14 / 749(1.9)$ & 0.57 \\
\hline Time from symptom onset to balloon inflation - $\min$ & & & 0.36 \\
\hline Median & 221 & 225 & \\
\hline Interquartile range & $160-329$ & $162-350$ & \\
\hline Time from arrival at hospital to balloon inflation $-\min$ & & & 0.92 \\
\hline Median & 100 & 97 & \\
\hline Interquartile range & 74-134 & $71-138$ & \\
\hline Killip class II, III, or IV — no./total no. (\%) & $199 / 2254(8.8)$ & $60 / 748(8.0)$ & 0.50 \\
\hline Renal insufficiency — no./total no. (\%)* & $328 / 2102(15.6)$ & $107 / 696(15.4)$ & 0.88 \\
\hline Anemia - no./total no. (\%) $†$ & $235 / 2130(11.0)$ & $54 / 715(7.6)$ & 0.008 \\
\hline Thrombocytopenia — no./total no. (\%) $\ddagger$ & $91 / 2186(4.2)$ & $30 / 733(4.1)$ & 0.93 \\
\hline Left ventricular ejection fraction — \% & & & 0.49 \\
\hline Median & 50 & 50 & \\
\hline Interquartile range & $44-59$ & $43-58$ & \\
\hline
\end{tabular}




\begin{tabular}{|c|c|c|c|}
\hline Variable & $\begin{array}{l}\text { Paclitaxel-Eluting } \\
\text { Stents }(\mathrm{N}=\mathbf{2 2 5 7})\end{array}$ & $\begin{array}{c}\text { Bare-Metal } \\
\text { Stents }(\mathrm{N}=749)\end{array}$ & P Value \\
\hline \multicolumn{4}{|l|}{ Use of antithrombin during $\mathrm{PCl}$ — no./total no. (\%) } \\
\hline Unfractionated heparin & $1123 / 2255(49.8)$ & $375 / 749(50.1)$ & 0.90 \\
\hline Bivalirudin & $1141 / 2252(50.7)$ & $379 / 745(50.9)$ & 0.92 \\
\hline $\begin{array}{l}\text { Use of glycoprotein IIb/IIla inhibitor during } \mathrm{PCl} \text { - no./total } \\
\text { no. (\%) }\end{array}$ & $1171 / 2253(52.0)$ & $385 / 748(51.5)$ & 0.81 \\
\hline \multicolumn{4}{|l|}{ Medications at discharge - no./total no. (\%) } \\
\hline Beta-blockers & $2048 / 2213(92.5)$ & $680 / 738(92.1)$ & 0.72 \\
\hline $\begin{array}{l}\text { Angiotensin-converting-enzyme inhibitors or receptor } \\
\text { blockers }\end{array}$ & $1840 / 2212(83.2)$ & $614 / 738(83.2)$ & 0.99 \\
\hline Statins & $2123 / 2212(96.0)$ & $708 / 738$ (95.9) & 0.96 \\
\hline \multicolumn{4}{|l|}{ Use of aspirin — no./total no. (\%) } \\
\hline At discharge & $2192 / 2213(99.1)$ & $728 / 738(98.6)$ & 0.35 \\
\hline At 30 days 9 & $2115 / 2148(98.5)$ & $700 / 712(98.3)$ & 0.78 \\
\hline At 6 mo & $2043 / 2096(97.5)$ & $682 / 694(98.3)$ & 0.23 \\
\hline At $1 \mathrm{yr} \mathbb{q}$ & $2019 / 2080(97.1)$ & $662 / 679(97.5)$ & 0.56 \\
\hline \multicolumn{4}{|l|}{ Use of thienopyridine - no./total no. (\%) } \\
\hline At discharge & $2200 / 2213(99.4)$ & $730 / 738(98.9)$ & 0.16 \\
\hline At 30 days 9 & $2127 / 2154(98.7)$ & $696 / 712(97.8)$ & 0.06 \\
\hline At 6 mo & $1989 / 2100(94.7)$ & $607 / 694(87.5)$ & $<0.001$ \\
\hline At 1 yr & $1522 / 2083(73.1)$ & $434 / 679(63.9)$ & $<0.001$ \\
\hline \multicolumn{4}{|c|}{$\begin{array}{l}\text { Renal insufficiency was defined as a creatinine clearance of less than } 60 \mathrm{ml} \text { per minute as calculated with the use of the } \\
\text { Cockcroft-Gault equation. } \\
\text { Anemia was defined, according to the World Health Organization criteria, as a hematocrit value at initial presentation } \\
\text { of less than } 39 \% \text { for men and less than } 36 \% \text { for women. } \\
\text { Thrombocytopenia was defined as less than } 150,000 \text { platelets per cubic millimeter. } \\
\text { The left ventricular ejection fraction was assessed visually on the contrast-enhanced left ventriculogram obtained at } \\
\text { baseline. } \\
\text { Patients were considered to have used aspirin or a thienopyridine if they had taken the drug on more than } 50 \% \text { of the } \\
\text { days since the previous study visit. }\end{array}$} \\
\hline
\end{tabular}

val for the difference in percentages, with a noninferiority margin of 3.0\%. Assuming a $7.5 \%$ rate of the safety end point of major adverse cardiovascular events in both stent groups, we calculated that the study would have $80 \%$ power to show the noninferiority of paclitaxel-eluting stents as compared with bare-metal stents for the primary safety end point.

Data were analyzed according to the group assignment, regardless of the treatment received. Categorical outcomes were compared by means of the chi-square test or Fisher's exact test. Continuous variables were compared by means of the Wilcoxon rank-sum test. The primary event analyses were performed with the use of timeto-event data (with data censored at the time of a patient's withdrawal from the study or at the last follow-up examination); the results of these analyses are shown with the use of KaplanMeier methods and were compared by means of the log-rank test. As a secondary analysis, timeupdated Cox proportional-hazards regression with adjustment for covariates was performed to adjust for baseline imbalances and differences in medication use between the groups over time.

\section{RESULTS}

\section{PATIENTS AND PROCEDURES}

Between March 25, 2005, and May 7, 2007, a total of 3602 patients with ST-segment elevation myocardial infarction who were undergoing primary PCI at 123 centers in 11 countries were randomly assigned to treatment with heparin plus a glyco- 
protein IIb/IIIa inhibitor (1802 patients) or to treatment with bivalirudin alone (1800 patients) (Fig. 1). PCI was subsequently performed in 3345 patients (92.9\%), of whom 3226 (96.4\%) underwent attempted stenting. Among those patients undergoing primary stenting, 3006 (93.2\%) were randomly assigned to receive either paclitaxel-eluting stents (2257 patients) or bare-metal stents (749). A total of 220 patients received stents but were not randomly assigned to a study group for a variety of reasons (Fig. 1).

The baseline features of the groups were well matched, except that there was a slightly higher percentage of current smokers in the group assigned to receive bare-metal stents and a slightly higher percentage of patients with baseline anemia in the group assigned to receive paclitaxeleluting stents (Table 1). The median age of the patients was 59.7 years, and $76.7 \%$ of the patients were men. The angiographic characteristics and procedural results were also similar between the groups except that the lesions in the patients assigned to receive paclitaxel-eluting stents were slightly longer, necessitating the use of slightly longer stents (Table 2). Compliance with taking aspirin was high in both groups throughout the 12 -month follow-up period. The rate of thienopyridine use was slightly higher at 6 and 12 months among patients in whom paclitaxel-eluting stents had been implanted than among those in whom bare-metal stents had been implanted.

\section{CLINICAL OUTCOMES}

The rate of the primary efficacy end point, ischemia-driven target-lesion revascularization at 12 months, was $4.5 \%$ in the paclitaxel-eluting-stent group as compared with $7.5 \%$ in the bare-metalstent group (hazard ratio with paclitaxel-eluting stents, 0.59 ; $95 \%$ confidence interval [CI], 0.43 to 0.83 ), which represented a benefit for 3 additional patients per 100 who were treated for 1 year with paclitaxel-eluting stents as compared with bare-metal stents ( $95 \% \mathrm{CI}, 0.9$ to $5.1 ; \mathrm{P}=0.002$ ) and a $41 \%$ relative hazard reduction with paclitaxel-eluting stents as compared with bare-metal stents (Table 3 and Fig. 2). The rate of ischemiadriven target-vessel revascularization at 12 months was also lower among patients treated with paclitaxel-eluting stents than among those treated with bare-metal stents $(5.8 \%$ vs. $8.7 \%$; hazard ratio, $0.65 ; 95 \%$ CI, 0.48 to $0.89 ; \mathrm{P}=0.006$ ). The 12 -month rates of the primary safety end point of major adverse cardiovascular events were similar between patients who received paclitaxel-eluting stents and those who received bare-metal stents $(8.1 \%$ and $8.0 \%$, respectively; hazard ratio with paclitaxeleluting stents, 1.02 ; $95 \% \mathrm{CI}, 0.76$ to 1.36 ; absolute difference, 0.1 percentage point; $95 \% \mathrm{CI},-2.1$ to $2.4 ; \mathrm{P}=0.01$ for noninferiority; $\mathrm{P}=0.92$ for superiority). The individual rates of death, reinfarction, stroke, and stent thrombosis were also similar in the two groups through 12 months of follow-up. The point estimates for the two primary end points were not significantly changed after correction for the baseline differences in smoking and anemia and follow-up use of thienopyridine agents (hazard ratio for ischemic target-lesion revascularization with paclitaxel-eluting stents, $0.62 ; 95 \% \mathrm{CI}, 0.44$ to $0.87 ; \mathrm{P}=0.006$; hazard ratio for major adverse cardiovascular events, 1.03; $95 \% \mathrm{CI}, 0.76$ to $1.40 ; \mathrm{P}=0.84)$. In logistic-regression analyses, there were no significant interactions between the initial pharmacologic group assignment (heparin plus a glycoprotein IIb/IIIa inhibitor or bivalirudin alone) and the assigned stent type with respect to the occurrence of the two primary end points $(\mathrm{P}=0.17$ for ischemic target-lesion revascularization and $\mathrm{P}=0.89$ for major adverse cardiovascular events).

\section{ANGIOGRAPHIC OUTCOMES}

Angiographic follow-up data at 13 months were available for 910 patients who received paclitaxeleluting stents (1081 lesions) and for 293 patients who received bare-metal stents (332 lesions) and were analyzed at the core angiographic laboratory. The rate of the major secondary efficacy end point, analysis-segment binary restenosis (which includes measurements within the stent and $5 \mathrm{~mm}$ proximal and distal to the stent) in all lesions, was $10.0 \%$ among lesions in the paclitaxel-elutingstent group as compared with $22.9 \%$ among lesions in the bare-metal-stent group, a difference of $56 \%$ (relative risk with paclitaxel-eluting stents, 0.44; $95 \%$ CI, 0.33 to 0.57 ; $<<0.001$ ). Among the 1062 lesions in the paclitaxel-eluting-stent group and the 328 in the bare-metal-stent group in which stents were implanted (Table 4), in-stent late luminal loss was less with paclitaxel-eluting stents than with bare-metal stents $(0.41 \pm 0.64 \mathrm{~mm}$ vs. $0.82 \pm 0.70 \mathrm{~mm}, \mathrm{P}<0.001$ ), and the rate of analysis-segment binary restenosis was lower $(9.6 \%$ vs. $23.2 \%, \mathrm{P}<0.001)$. There were no significant differences in the rates of reocclusion of the infarct- 


\begin{tabular}{|c|c|c|c|}
\hline Variable & $\begin{array}{l}\text { Paclitaxel-Eluting } \\
\text { Stents ( }=2257)\end{array}$ & $\begin{array}{c}\text { Bare-Metal } \\
\text { Stents }(N=749)\end{array}$ & P Value \\
\hline Lesions treated & & & 0.12 \\
\hline Total no. & 2525 & 820 & \\
\hline No. per patient & $1.1 \pm 0.4$ & $1.1 \pm 0.4$ & \\
\hline$\geq 2$ lesions treated - no. of patients/total no. (\%) & $248 / 2236(11.1)$ & $67 / 742(9.0)$ & 0.11 \\
\hline$\geq 2$ vessels treated - no. of patients/total no. (\%) & $101 / 2236(4.5)$ & $23 / 742(3.1)$ & 0.09 \\
\hline \multicolumn{4}{|l|}{ Type of stent — no. of lesions/total no. (\%) } \\
\hline Paclitaxel-eluting & $2485 / 2525(98.4)$ & $1 / 820(0.1)$ & - \\
\hline Other drug-eluting & $0 / 2525$ & $1 / 820(0.1)$ & - \\
\hline Bare-metal & $28 / 2525(1.1)$ & $813 / 820(99.1)$ & - \\
\hline \multicolumn{4}{|l|}{ Site of infarct lesion - no. of lesions/total no. (\%) } \\
\hline Left anterior descending coronary artery & $1006 / 2525(39.8)$ & $347 / 820(42.3)$ & 0.21 \\
\hline Left circumflex coronary artery & $374 / 2525(14.8)$ & $132 / 820(16.1)$ & 0.37 \\
\hline Right coronary artery & $1138 / 2525(45.1)$ & $338 / 820(41.2)$ & 0.05 \\
\hline Left main coronary artery & $7 / 2525(0.3)$ & $3 / 820(0.4)$ & 0.71 \\
\hline Saphenous-vein graft & $30 / 2498(1.2)$ & $6 / 811(0.7)$ & 0.27 \\
\hline $\begin{array}{l}\text { Implantation of at least one stent attempted } \\
\qquad- \text { no. of lesions/total no. (\%) }\end{array}$ & $2501 / 2525(99.0)$ & $815 / 820(99.4)$ & 0.36 \\
\hline $\begin{array}{l}\text { Direct stenting attempted } \\
\qquad- \text { no. of lesions/total no. (\%) } \dagger\end{array}$ & $734 / 2501(29.3)$ & $264 / 815(32.4)$ & 0.10 \\
\hline No. of stents implanted per patient & $1.5 \pm 0.9$ & $1.4 \pm 0.7$ & $<0.001$ \\
\hline Total stent length per patient $-\mathrm{mm}$ & $30.8 \pm 17.8$ & $27.3 \pm 14.9$ & $<0.001$ \\
\hline Maximum balloon diameter per lesion - $\mathrm{mm}$ & $3.20 \pm 0.61$ & $3.18 \pm 0.58$ & 0.84 \\
\hline Maximum pressure per lesion — atm & $14.9 \pm 3.5$ & $14.9 \pm 3.3$ & 0.98 \\
\hline Aspiration catheter used — no. of patients/total no. (\%) & $255 / 2246(11.4)$ & $80 / 745(10.7)$ & 0.64 \\
\hline \multicolumn{4}{|l|}{ Baseline TIMI flow grade — no. of vessels/total no. (\%) $\Varangle$} \\
\hline 0 or 1 & $1424 / 2348(60.6)$ & $442 / 770(57.4)$ & 0.11 \\
\hline 2 & $320 / 2348(13.6)$ & $117 / 770(15.2)$ & 0.28 \\
\hline 3 & $604 / 2348(25.7)$ & $211 / 770(27.4)$ & 0.36 \\
\hline \multicolumn{4}{|l|}{ Baseline quantitative angiographic findings for lesions } \\
\hline Reference-vessel diameter $-\mathrm{mm}$ & $2.89 \pm 0.51$ & $2.90 \pm 0.50$ & 0.75 \\
\hline Minimal luminal diameter $-\mathrm{mm}$ & $0.35 \pm 0.45$ & $0.35 \pm 0.45$ & 0.81 \\
\hline Stenosis — \% of vessel diameter & $87.6 \pm 15.4$ & $87.4 \pm 15.4$ & 0.83 \\
\hline Lesion length $-\mathrm{mm}$ & $17.5 \pm 10.1$ & $16.2 \pm 8.8$ & 0.006 \\
\hline \multicolumn{4}{|l|}{ Final TIMI flow grade — no. of vessels/total no. (\%) } \\
\hline 0 or 1 & $40 / 2346(1.7)$ & $7 / 771(0.9)$ & 0.12 \\
\hline 2 & $252 / 2346(10.7)$ & $72 / 771(9.3)$ & 0.27 \\
\hline 3 & $2054 / 2346(87.6)$ & $692 / 771(89.8)$ & 0.10 \\
\hline \multicolumn{4}{|l|}{ Final quantitative angiographic findings for lesions } \\
\hline Reference-vessel diameter $-\mathrm{mm}$ & $2.93 \pm 0.51$ & $2.95 \pm 0.50$ & 0.57 \\
\hline Minimal luminal diameter $-\mathrm{mm}$ & $2.36 \pm 0.55$ & $2.37 \pm 0.52$ & 0.38 \\
\hline Stenosis - \% of vessel diameter & $19.9 \pm 11.6$ & $19.5 \pm 11.1$ & 0.33 \\
\hline
\end{tabular}

* Plus-minus values are means \pm SD. TIMI denotes Thrombolysis in Myocardial Infarction.

$\dagger$ Direct stenting refers to the implantation of a stent without balloon predilation.

$¥$ TIMI flow is graded on a scale of 0 to 3 , with a higher grade indicating better flow. 


\begin{tabular}{|c|c|c|c|c|c|}
\hline \multirow[t]{2}{*}{ Outcome } & \multicolumn{2}{|c|}{ Cumulative No. of Events } & \multicolumn{2}{|c|}{$\begin{array}{l}\text { Kaplan-Meier Estimate } \\
\text { of Cumulative Event-Rate }\end{array}$} & \multirow[t]{2}{*}{ P Value } \\
\hline & $\begin{array}{l}\text { Paclitaxel-Eluting } \\
\text { Stents }(N=2257)\end{array}$ & $\begin{array}{c}\text { Bare-Metal } \\
\text { Stents }(N=749)\end{array}$ & $\begin{array}{l}\text { Paclitaxel-Eluting } \\
\text { Stents }(N=2257)\end{array}$ & $\begin{array}{c}\text { Bare-Metal } \\
\text { Stents }(N=749)\end{array}$ & \\
\hline Ischemia-driven target-lesion revascularization †† & 98 & 54 & 4.5 & 7.5 & 0.002 \\
\hline $\mathrm{PCl}$ & 88 & 48 & 4.0 & 6.6 & 0.004 \\
\hline CABG & 10 & 7 & 0.5 & 1.0 & 0.12 \\
\hline Ischemia-driven target-vessel revascularizationł & 126 & 63 & 5.8 & 8.7 & 0.006 \\
\hline $\mathrm{PCl}$ & 109 & 56 & 5.0 & 7.7 & 0.006 \\
\hline CABG & 18 & 8 & 0.8 & 1.1 & 0.48 \\
\hline Major adverse cardiovascular events』 & 181 & 59 & 8.1 & 8.0 & 0.92 \\
\hline Death & 78 & 26 & 3.5 & 3.5 & 0.98 \\
\hline Cardiac & 54 & 20 & 2.4 & 2.7 & 0.67 \\
\hline Noncardiac & 24 & 6 & 1.1 & 0.8 & 0.55 \\
\hline Reinfarction & 81 & 33 & 3.7 & 4.5 & 0.31 \\
\hline Q-wave & 45 & 14 & 2.0 & 1.9 & 0.83 \\
\hline Non-Q-wave & 39 & 19 & 1.8 & 2.7 & 0.16 \\
\hline Death or reinfarction & 152 & 52 & 6.8 & 7.0 & 0.83 \\
\hline Stroke & 23 & 5 & 1.0 & 0.7 & 0.39 \\
\hline Stent thrombosis $₫$ & 70 & 25 & 3.2 & 3.4 & 0.77 \\
\hline Definite & 58 & 22 & 2.6 & 3.0 & 0.60 \\
\hline Probable & 12 & 3 & 0.5 & 0.4 & 0.65 \\
\hline
\end{tabular}

* CABG denotes coronary-artery bypass grafting, and PCI percutaneous coronary intervention.

$\uparrow$ Ischemia-driven target-lesion revascularization (the primary efficacy end point) refers to a procedure to treat recurrent ischemia due to restenosis at the site of the original target lesion (including a 5-mm proximal or distal margin outside the stent).

$\uparrow$ Ischemia-driven target-vessel revascularization refers to a procedure to treat recurrent ischemia due either to restenosis within or just outside the stent or to a lesion anywhere else in the same epicardial coronary artery or its branches.

$\int$ The composite primary safety end point of major adverse cardiovascular events comprised death, myocardial infarction, stroke, and stent thrombosis.

9 Stent thrombosis was defined according to the Academic Research Consortium classification. ${ }^{15}$

related artery (TIMI flow grade of 0 or 1 ), ulceration, ectasia, or aneurysm formation between the two stent groups.

\section{I S C USSION}

In this international, prospective, controlled trial involving patients with ST-segment elevation myocardial infarction who were undergoing primary PCI, in which more than $93 \%$ of the patients who received stents were randomly assigned to a studystent group, treatment with paclitaxel-eluting stents as compared with otherwise identical bare-metal stents resulted in a significantly reduced rate of angiographically assessed restenosis and in a significantly decreased rate of recurrent ischemia necessitating repeat revascularization by means of
PCI or CABG. Moreover, paclitaxel-eluting stents were noninferior to bare-metal stents with respect to the primary composite safety end point of major adverse cardiovascular events at 12 months, with similar rates of the individual components of the composite safety end point (i.e., death, reinfarction, stroke, and stent thrombosis). The HORIZONS-AMI trial thus provides data indicating that paclitaxeleluting stents can be used in patients with evolving ST-segment elevation myocardial infarction.

A meta-analysis of previous small-to-moderatesize randomized trials showed that for each 1000 patients with ST-segment elevation myocardial infarction who received drug-eluting stents as compared with bare-metal stents, approximately 76 fewer required target-vessel revascularization within 1 year. ${ }^{10}$ In contrast, in our trial, in which more 


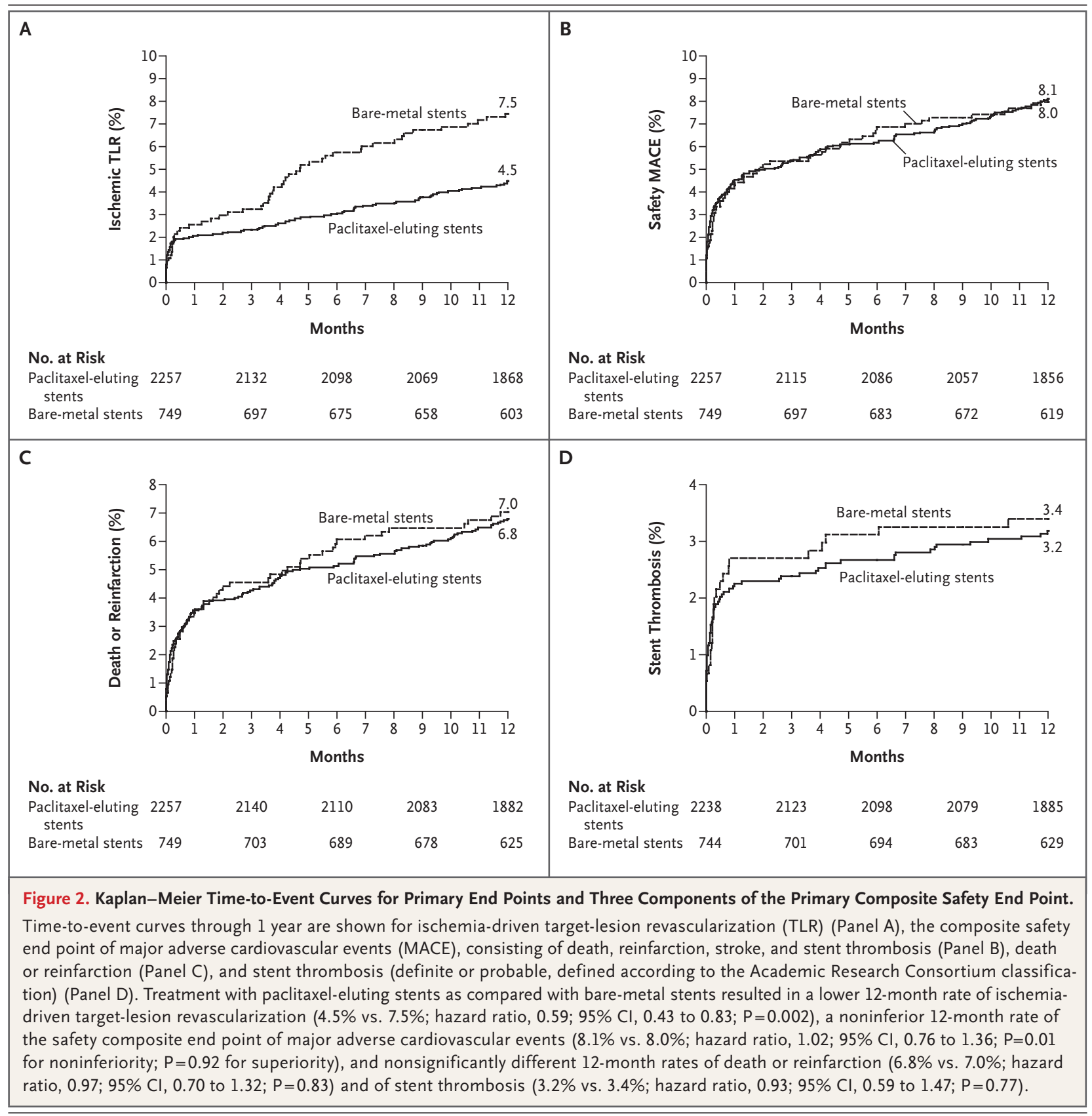

than 3000 patients were randomly assigned to a stent group, approximately 30 fewer per 1000 patients who received paclitaxel-eluting stents as compared with a bare-metal stents required targetvessel revascularization within 1 year. Since relatively few patients were excluded from our trial because of anatomical complexity, the most likely explanation for the differences between these findings is that routine angiographic follow-up was performed before the assessment of the pri- mary clinical end point in most of the earlier randomized trials, a protocol-specific process that artificially increases the rates of revascularization (the "oculostenotic reflex"). ${ }^{11,12}$ In contrast, routine angiographic follow-up in the present trial was not performed until 1 month after ascertainment of the primary 12-month clinical end points, thereby permitting a more accurate and realistic determination of treatment-related effects. Also, in the present study, the $41 \%$ rela- 


\begin{tabular}{|c|c|c|c|}
\hline Finding & $\begin{array}{l}\text { Paclitaxel-Eluting } \\
\text { Stents }\end{array}$ & $\begin{array}{l}\text { Bare-Metal } \\
\text { Stents }\end{array}$ & P Value \\
\hline \multicolumn{4}{|l|}{ TIMI flow grade — no. of vessels/total no. (\%) } \\
\hline 0 or 1 & $27 / 964(2.8)$ & $11 / 302(3.6)$ & 0.45 \\
\hline 2 & $67 / 964(7.0)$ & $15 / 302(5.0)$ & 0.22 \\
\hline 3 & $870 / 964(90.2)$ & $276 / 302(91.4)$ & 0.55 \\
\hline \multicolumn{4}{|l|}{ Quantitative coronary angiography of lesions $†$} \\
\hline Reference-vessel diameter $-\mathrm{mm}$ & $2.91 \pm 0.48$ & $2.90 \pm 0.48$ & 0.94 \\
\hline \multicolumn{4}{|l|}{ Minimal luminal diameter $-\mathrm{mm}$} \\
\hline In-stent & $2.36 \pm 0.75$ & $1.98 \pm 0.82$ & $<0.001$ \\
\hline In-segment & $2.09 \pm 0.68$ & $1.84 \pm 0.76$ & $<0.001$ \\
\hline \multicolumn{4}{|l|}{ Late loss - $\mathrm{mm}$} \\
\hline In-stent & $0.41 \pm 0.64$ & $0.82 \pm 0.70$ & $<0.001$ \\
\hline In-segment & $0.30 \pm 0.56$ & $0.59 \pm 0.64$ & $<0.001$ \\
\hline \multicolumn{4}{|l|}{ Stenosis - $\%$ of vessel diameter } \\
\hline In-stent & $18.7 \pm 22.8$ & $32.6 \pm 24.9$ & $<0.001$ \\
\hline In-segment & $28.6 \pm 19.4$ & $37.4 \pm 22.1$ & $<0.001$ \\
\hline \multicolumn{4}{|l|}{ Binary restenosis - no. of lesions/total no. (\%) } \\
\hline In-stent & $87 / 1062(8.2)$ & $69 / 328(21.0)$ & $<0.001$ \\
\hline In-segment & $102 / 1062(9.6)$ & $76 / 328(23.2)$ & $<0.001$ \\
\hline Aneurysm formation — no. of lesions/total no. (\%)† & $4 / 1059(0.4)$ & $3 / 328(0.9)$ & 0.37 \\
\hline Ulceration — no. of lesions/total no. (\%)† & $5 / 1060(0.5)$ & $2 / 328(0.6)$ & 0.67 \\
\hline Ectasia - no. of lesions/total no. (\%) $\dagger$ & $7 / 1059(0.7)$ & $3 / 328(0.9)$ & 0.71 \\
\hline
\end{tabular}

* Plus-minus values are means \pm SD. TIMI denotes Thrombolysis in Myocardial Infarction.

$\dagger$ Data are for stented lesions only; no stent was implanted in 15 lesions in the paclitaxel-eluting-stent group and 4 lesions in the bare-metal-stent group.

tive hazard reduction in the rate of clinically assessed restenosis (ischemia-driven target-lesion revascularization) at 12 months with paclitaxeleluting stents as compared with bare-metal stents was somewhat less than the $56 \%$ relative reduction in the rate of angiographically assessed restenosis at 13 months. This difference may be due to the occasional occurrence of restenosis that does not provoke ischemia or symptoms in an infarcted myocardial territory. This possibility, coupled with the elimination of unnecessary revascularization procedures because we did not perform routine angiographic follow-up before assessing the primary clinical end point, explains the relatively low 1-year rate of ischemia-driven target-lesion revascularization after implantation of bare-metal stents that was observed in the present trial. Longer-term follow-up will show whether the marked reduction in angiographical- ly assessed restenosis with paclitaxel-eluting stents as compared with bare-metal stents results in greater incremental clinical benefits beyond 12 months.

The results of the present study are otherwise consistent with those of earlier, smaller, randomized studies, in which 1-year mortality rates were similar between patients with ST-segment elevation myocardial infarction who were treated with drug-eluting stents and those who were treated with bare-metal stents. ${ }^{10}$ In contrast, in large, nonrandomized, observational studies of data from state registries in Massachusetts, New York, and New Jersey, in which multivariable and propensity-score adjustments were used to correct for measured baseline differences, the results suggested that drug-eluting stents, as compared with bare-metal stents, significantly reduce mortality among patients with ST-segment elevation 
myocardial infarction. ${ }^{17-19}$ However, scrutiny of the hazard curves in these registry studies indicates that much of the relative survival benefit with drug-eluting stents occurred within 30 days after stent implantation, before the known benefits of drug-eluting stents in reducing restenosis are apparent. The inability to adjust for unmeasured confounders (including coexisting conditions and other factors that make noncompliance with clopidogrel therapy likely in patients selected to receive bare-metal stents) probably explains the observed reduction in mortality with drug-eluting stents in these nonrandomized studies. In contrast, the results of randomized trials that now include more than 6500 patients strongly suggest that survival within 1 year after implantation is similar, but not improved, with drug-eluting stents as compared with bare-metal stents among patients with ST-segment elevation myocardial infarction. Similarly, the present trial confirms and extends the results of earlier randomized studies ${ }^{10}$ that showed similar rates of stent thrombosis and reinfarction at 1 year with drug-eluting stents and bare-metal stents in patients with STsegment elevation myocardial infarction.

Several limitations of the present study deserve comment. First, logistic complexities necessitated an open-label design. Potential bias was mitigated by high rates of compliance with the protocol procedures and the use of blinded clinical-event adjudication and core-laboratory assessments. Second, although the rate of use of thienopyridine agents was slightly greater between 6 and 12 months in the group that received paclitaxel-eluting stents than in the group that received baremetal stents, the point estimates for the primary efficacy and safety end points were not significantly altered after multivariable adjustment for this imbalance. Third, although the nearly identical rates of the safety end point of major adverse cardiovascular events in the two stent groups suggest that paclitaxel-eluting stents are safe in patients with evolving ST-segment elevation myocardial infarction at 1 year, longer-term follow-up is required to characterize the late safety and efficacy profiles of paclitaxel-eluting stents in patients with ST-segment elevation myocardial infarction, especially as the use of dual antiplatelet agents declines over time after stent implantation. This point is particularly germane because the increased risk of stent thrombosis with drug-eluting stents as compared with bare-metal stents may emerge only beyond 1 year after stent implantation $^{3}$ and because at least one previous study ${ }^{20}$ (but not all ${ }^{17-19,21}$ ) has suggested that the incremental benefits of drug-eluting stents in patients with ST-segment elevation myocardial infarction diminish with late follow-up. Fourth, although the present trial had relatively few exclusion criteria, the results apply only to patients who were enrolled; specifically, patients with unprotected left main coronary artery disease, patients with bifurcation lesions requiring planned dual-stent treatment, and patients who were unlikely to comply with at least 6 months of dual antiplatelet therapy were excluded, and relatively few patients with cardiogenic shock were enrolled. Further studies are also required to determine which patients and lesions are most likely to benefit from drug-eluting stents, the long-term safety of drug-eluting stents after discontinuation of thienopyridine treatment, and the relative cost-effectiveness of such stents in patients with ST-segment elevation myocardial infarction, all of which are important considerations in deciding which type of stent to use during primary PCI. Finally, our findings apply only to paclitaxel-eluting stents; future large-scale trials are required to determine the relative safety and efficacy of other drug-eluting stents in patients with ST-segment elevation myocardial infarction, especially stents that are more potent inhibitors of neointimal proliferation..$^{22,23}$

In conclusion, the present trial shows that in patients with evolving ST-segment elevation myocardial infarction who are undergoing primary PCI with stent implantation, the use of paclitaxeleluting stents, as compared with bare-metal stents, reduces angiographic restenosis and recurrent ischemia necessitating repeat revascularization procedures within the first year. No safety concerns were apparent at 1 year.

Sponsored by the Cardiovascular Research Foundation, with grant support from Boston Scientific Corporation and the Medicines Company.

Dr. Stone reports receiving consulting fees from Eli Lilly, Medtronic, Biosensors, and XTENT and grant support from Boston Scientific, Abbott Vascular, and the Medicines Company, and owning equity in Devax and XTENT; Dr. Pocock, receiving consulting fees from the Medicines Company and Boston Scientific, lecture fees from the Medicines Company, and grant support from the Medicines Company and Boston Scientific; Dr. Gersh, receiving consulting fees from AstraZeneca, Boston Scientific, Bristol-Myers Squibb, and Abbott Laboratories and owning equity in CV Therapeutics; Dr. Dangas, receiving consulting fees from Boston Scientific, the Medicines Company, and Eli Lilly, and lecture fees and grant support from Boston Scientific; Dr. Wong, receiving lecture fees from the Medicines Company and grant support from Boston Scientific and the Medicines Company; Dr. 
Guagliumi, receiving consulting fees from Boston Scientific, lecture fees from the Medicines Company and Medtronic, and grant support from Medtronic, Boston Scientific, and Labcoat; Dr Dudek, receiving consulting and lecture fees from Abbott, Adamed, Biotronik, Balton, Bayer, B. Braun, BioMatrix, Boston Scientific, Boehringer Ingelheim, Bristol-Myers Squibb, Cordis, Cook, Eli Lilly, Eurocor, GlaxoSmithKline, Invatec, Medtronic, the
Medicines Company, Merck, Nycomed, OrbusNeich, Pfizer, Possis, Promed, Sanofi-Aventis, Siemens, Solvay, Terumo, and Tyco; Dr. Möckel, receiving consulting and lecture fees from the Medicines Company; and Dr. Mehran, receiving consulting fees from Abbott Vascular and lecture fees from Boston Scientific, Cordis, the Medicines Company, and Medtronic. No other potential conflict of interest relevant to this article was reported.

\section{APPENDIX}

The following investigators and institutions participated in the HORIZONS-AMI Trial: Executive Committee: G.W. Stone (principal investigator and chair), Columbia University Medical Center and the Cardiovascular Research Foundation, New York; B.R. Brodie, LeBauer Cardiovascular Research Foundation and Moses Cone Hospital, Greensboro, NC; D.A. Cox, Mid Carolina Cardiology, Charlotte, NC; C.L. Grines, William Beaumont Hospital, Royal Oak, MI; B.D. Rutherford, St. Luke's Hospital, Kansas City, MO. Pharmacology Committee: D. Bhatt, Cleveland Clinic Foundation, Cleveland; G. Dangas, Columbia University Medical Center and the Cardiovascular Research Foundation, New York; F. Feit, New York University, New York; M. Ohman, Duke University Medical Center, Durham, NC. European Steering Committee: H. Bonnier, Catharina Hospital, Eindhoven, the Netherlands; A. Colombo, Colombus Hospital, Milan; E. Garcia, Hospital Universitario Gregorio Maranon, Madrid; E. Grube, Heart Center Siegburg, Siegburg, Germany; G. Guagliumi, Ospedali Riuniti di Bergamo, Bergamo, Italy; A. Kastrati, Deutsches Herzzentrum, Technische Universität, Munich, Germany; P. Serruys, Thoraxcenter, Rotterdam, the Netherlands; H. Suryapranata, Hospital De Weezenlanden, Zwolle, the Netherlands. Country Leaders: the Netherlands: H. Bonnier, H. Suryapranata; Italy: A. Colombo, G. Guagliumi; Spain: E. Garcia; Germany: E. Grube, A. Kastrati; Israel: Y. Almagor; United Kingdom: A. Banning; Argentina: J. Belardi, L. Grinfeld; Poland: D. Dudek; Austria: K. Huber; Norway: D. Nilsen; Sweden: G. Olivecrona; Denmark: L. Rasmussen. Clinical Endpoints Committee: Cardiovascular Research Foundation Data Center, New York, S.C. Wong (chair). Field Officers: M. Farkouh (chair), M. Attubato, G. Dangas, F. Feit, R. Mehran. Site Management and Data Monitoring: J. Tyson and Associates (United States), D-Target (Europe), Tango (South America). Data Management: E-trials, Morrisville, NC, D. Winsted (manager). Data Coordination and Analysis: Cardiovascular Research Foundation Data Center, New York, R. Mehran (director), L. Gambone, I. Bihl (operations), H. Parise (statistics). Data Safety and Monitoring Board: B.J. Gersh (chair), Mayo Clinic, Rochester, MN; D. Faxon, Brigham and Women's Hospital, Boston; S. King, Fuqua Heart Center, Atlanta; S.J. Pocock, London School of Hygiene and Tropical Medicine, London; D.O. Williams, Rhode Island Hospital, Providence. Qualitative and Quantitative Coronary Angiographic Core Laboratory Analysis: Cardiovascular Research Foundation, New York, A.J. Lansky (director), E. Cristea (operations). Qualitative and Quantitative Electrocardiographic Core Laboratory Analysis: Cardiovascular Research Foundation, New York, J. Reiffel (director). Intravascular Ultrasound Core Laboratory Analysis: Cardiovascular Research Foundation, New York, G. Mintz (director). Biomarker Substudy Core Laboratory: BioSite, San Diego, CA.

For a full list of participating countries (with total enrollment), hospitals, and principal investigators, see the Supplementary Appendix (available with the full text of this article at NEJM.org).

\section{REFERENCES}

1. Stone GW, Grines CL, Cox DA, et al. Comparison of angioplasty with stenting, with or without abciximab, in acute myocardial infarction. N Engl J Med 2002;346: 957-66.

2. De Luca G, Suryapranata H, Stone GW, et al. Coronary stenting versus balloon angioplasty for acute myocardial infarction: a meta-regression analysis of randomized trials. Int J Cardiol 2008;126: 37-44.

3. Stone GW, Moses JW, Ellis SG, et al. Safety and efficacy of sirolimus- and paclitaxel-eluting coronary stents. N Engl J Med 2007;356:998-1008.

4. Mauri L, Hsieh WH, Massaro JM, Ho KK, D'Agostino R, Cutlip DE. Stent thrombosis in randomized clinical trials of drug-eluting stents. N Engl J Med 2007; 356:1020-9.

5. Win HK, Caldera AE, Maresh K, et al. Clinical outcomes and stent thrombosis following off-label use of drug-eluting stents. JAMA 2007;297:2001-9.

6. Beohar N, Davidson CJ, Kip KE, et al. Outcomes and complications associated with off-label and untested use of drugeluting stents. JAMA 2007;297:1992-2000. 7. Nakazawa G, Finn AV, Joner M, et al Delayed arterial healing and increased late stent thrombosis at culprit sites after drug-eluting stent placement for acute myocardial infarction patients: an autopsy study. Circulation 2008;118:1138-45.

8. Urban P, Gershlick AH, Guagliumi G et al. Safety of coronary sirolimus-eluting stents in daily clinical practice: one-year follow-up of the e-Cypher registry. Circulation 2006;113:1434-41.

9. de la Torre-Hernández JM, Alfonso $\mathrm{F}$ Hernández $\mathrm{F}$, et al. Drug-eluting stent thrombosis: results from the multicenter Spanish registry ESTROFA (Estudio ESpañol sobre TROmbosis de stents FArmacoactivos). J Am Coll Cardiol 2008; 51:986-90.

10. De Luca G, Stone GW, Suryapranata $\mathrm{H}$, et al. Efficacy and safety of drug-eluting stents in ST-segment elevation myocardial infarction: a meta-analysis of randomized trials. Int J Cardiol 2009;133: 213-22.
11. ten Berg JM, Kelder JC, Suttorp MJ, Verheugt FW, Thijs Plokker HW. Influence of planned six-month follow-up angiography on large outcome after percutaneous coronary intervention: a randomized study. J Am Coll Cardiol 2001;38:1061-9.

12. Pinto DS, Stone GW, Ellis SG, et al. Impact of routine angiographic follow-up on the clinical benefits of paclitaxel-eluting stents: results from the TAXUS-IV trial. J Am Coll Cardiol 2006;48:32-6.

13. Mehran R, Brodie B, Cox DA, et al. The Harmonizing Outcomes with RevasculariZatiON and Stents in Acute Myocardial Infarction (HORIZONS-AMI) Trial: study design and rationale. Am Heart J 2008;156:44-56.

14. Stone GW, Witzenbichler B, Guagliumi $\mathrm{G}$, et al. Bivalirudin during primary $\mathrm{PCI}$ in acute myocardial infarction. $\mathrm{N}$ Engl J Med 2008;358:2218-30.

15. Cutlip DE, Windecker S, Mehran R, et al. Clinical end points in coronary stent trials: a case for standardized definitions. Circulation 2007;115:2344-51.

16. Lansky A, Popma J. Qualitative and 
quantitative angiography. In: Topol EJ, ed. Textbook of interventional cardiology. Philadelphia: W.B. Saunders, 1999:725-47. 17. Mauri L, Silbaugh TS, Garg P, et al. Drug-eluting or bare-metal stents for acute myocardial infarction. N Engl J Med 2008; 359:1330-42.

18. Hannan EL. Outcomes of drug-eluting vs. bare-metal stents for STEMI in New York. New York: Cardiovascular Research Foundation. (Accessed April 16, 2009, at http://www.tctmd.com/Show. aspx?id=72376.)

19. Vagaonescu I. The multicenter New Jersey MIDAS DES vs. BMS registry in pa- tients with AMI: late follow-up outcomes. (Accessed April 13, 2009, at http://www. tctmd.com/Show.aspx?id=73294.)

20. Daemen J, Tanimoto S, García-García HM, et al. Comparison of three-year clinical outcome of sirolimus- and paclitaxeleluting stents versus bare metal stents in patients with ST-segment elevation myocardial infarction (from the RESEARCH and T-SEARCH Registries). Am J Cardiol 2007;99:1027-32.

21. Valgimigli M, Campo G, Arcozzi C, et al. Two-year clinical follow-up after sirolimus-eluting versus bare-metal stent implantation assisted by systematic glycopro- tein IIb/IIIa inhibitor infusion in patients with myocardial infarction: results from the STRATEGY study. J Am Coll Cardiol 2007;50:138-45.

22. Moses JW, Leon MB, Popma JJ, et al. Sirolimus-eluting stents versus standard stents in patients with stenosis in a native coronary artery. N Engl J Med 2003;349: 1315-23.

23. Stone GW, Midei M, Newman W, et al. Comparison of an everolimus-eluting stent and a paclitaxel-eluting stent in patients with coronary artery disease: a randomized trial. JAMA 2008;299:1903-13.

Coppright (c) 2009 Massachusetts Medical Society.

ELECTRONIC ACCESS TO THE JOURNAL'S CUMULATIVE INDEX

At the Journal's site on the World Wide Web (NEJM.org), you can search an index of all articles published since January 1975 (abstracts 1975-1992, full text 1993-present). You can search by author,

key word, title, type of article, and date. The results will include the citations for the articles plus links to the full text of articles published since 1993.

For nonsubscribers, time-limited access to single articles and 24-hour site access can also be ordered for a fee through the Internet (NEJM.org). 